\title{
Parametric Optimization of Variable Compression Ratio Diesel Engine Fueled with PalmSeedBiodiesel and its Blend using the Taguchi Method for SFC
}

\author{
Chandramaulisinh A. Parmar ${ }^{1}$, Dr. Tushar M Patel ${ }^{2}$,Pragna R Patel ${ }^{3}$, \\ Gaurav P Rathod ${ }^{4}$ \\ ${ }^{I}$ M.E. Scholar, Mechanical Department, LDRP-ITR, Gandhinagar, India. \\ ${ }^{2}$ Professor, Mechanical Department, LDRP-ITR, Gandhinagar, India. \\ ${ }^{3}$ Assistant Professor, Mechanical Department, LDRP-ITR, Gandhinagar, India. \\ ${ }^{4}$ Lecturer, Government Polytechnic, Godhra, India.
}

\begin{abstract}
This study was initiated to find the Specific Fuel Consumption (SFC) of single cylinder diesel engine operating on palm seed biodiesel and compare them with SFC of engine when operated on pure diesel and blend of 50\% diesel and 50\% palm seed biodiesel. The aim of this study was to determine and compare the effects of variable parameters like Blend ratio, Compression ratio, Injection pressure and load on performance parameter, Specific fuel consumption. Since there are higher number of parameters and levels, the number of probable models are high. So, for selection of optimum parameters, huge analysis work is required which takes somuch time. To neglect this problem, Taguchi method is used. The set of combination for factors and levels are achieved with the help of orthogonal array.
\end{abstract}

Keywords: Palm seed Biodiesel, Compression ratio, Load, Injection pressure, Specific Fuel Consumption, Taguchi method, Orthogonal Array

\section{Introduction}

There are so many environmental and pollution problems today. Fuels prices are also increasing day by day. In this scenario it is needed to find an alternative fuel for internal combustion engines which is producing less pollution and are lower in price. Several alternate fuels are tried by various researches. An experimental study has been carried out for palm seed biodiesel blended with diesel used in a single cylinder diesel engine. Palm seed biodiesel presents a very promising scenario of functioning as alternative fuels to fossil diesel fuel. The properties of these can be compared favourably with the characteristics required for internal combustion engine fuels especially direct injection (diesel) engine. In this work, Taguchi method is used for doing optimization. Design of experiments (DOE) is a systematic method to determine the relationship between factors affecting a process and the output of that process. In other words, it is used to find cause-and-effect relationships. This information is needed to manage process inputs in order to optimize the output. So here, set of combination for varying parameters are obtained by orthogonal array. Orthogonal array is very important is this method. It helps in studying total number of variables by decreasing number of trials. Different Orthogonal Arrays are available in Minitab software which is designed by number of factors and levels. In this work, four factors and 2-3-level design is adopted. So here, we have selected L9 $\left(3^{\wedge} 4\right)$ design. In which no. of experiments are 9, no. of factors are 4 and levels are mixed 2-3 level. Then results are obtained by doing experiments as per above method and optimum set of input parameters are found which has minimum Specific Fuel Consumption.

\section{Literature Review}

Liaquat et al. (2013) said that during short term engine operation, renewable fuels derived from vegetable oils, are capable of providing good engine performance [1]. Mofijur et al. (2014) studied that as the reserves of fossil energy resources are becoming limited and decreasing day by day, discovering alternative energy sources has been becoming one of the global agenda. They said that biodiesel has been gaining popularity among the researchers as one of the alternative energy sources due to potential capacity of reducing dependency on fossil diesel fuel, decreasing environmental pollutants, etc. [2].Tushar Patel et al. (2015) studied that in the statistical design of experiments, Taguchi method is a collection of a mathematical and statistical techniques useful for the parametric optimization and analysis of problem in which a response of interest is influenced by several variables and the objective is to optimize this response [3]. Tushar Patel et al. (2015) studied that Taguchi method is a simplest method of optimizing experimental parameters in less number of trials. The number of parameters involved in the experiment determines the number of trials required for the experiment [4]. Mustafa et al. (2016) investigated on Taguchi's design of experiment method and analysis of variance (ANOVA) applied in order to find optimum operating parameters giving the best engine performance 
Parametric Optimization of Variable Compression Ratio Diesel Engine Fueled with Palm Seed ..

and exhaust emissionswith a minimum number of the engine tests in a spark ignition (SI) engine fueled with pure gasoline, ethanol and methanol. They said that Taguchi method makes statistical design by using the orthogonal array and also offers an opportunity to reduce the number of experiments. Taguchi technique computes a signal-to-noise $(\mathrm{S} / \mathrm{N})$ ratio based on experimental data [5].

\section{Methodology}

It is needed to adopt such a methodology that it increases efficiency and decreases specific fuel consumption. Taguchi's design approach employs two designs called the inner and outerarray. The Taguchi experiment is the cross product of these two arrays. A Taguchi experiment repeats the outer array design for each run of the inner array. The response variable in the data analysis is not the raw response or quality characteristic; it is the signal-to-noise ratio.Figure 1 shows the flow chart of Taguchi method.

Steps of the experiment:

1-Defining goal

2-Selecting Parameter

3-Selecting level

4-Selecting orthogonal array

5-Conducting Experiment

6-Plotting curves and doing performance analysis

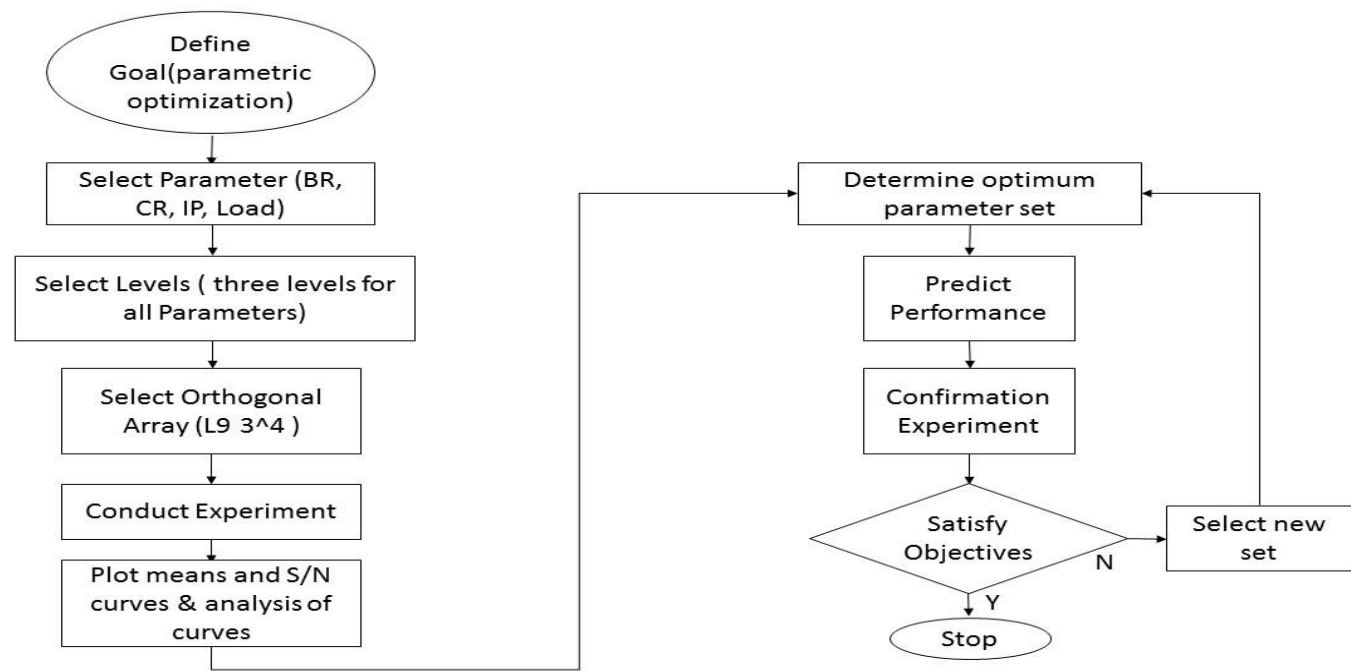

Fig 1: Flow chart of Taguchi method [6]

\section{Factors and levels}

In this practical, four factors and 2-3-level design is adopted. So here, we have selected L9 ( $\left.3^{\wedge} 4\right)$ orthogonal array design. In which no. of experiments are 9, no. of factors are 4 and levels are mixed 2-3 level. The variable parameters can be varied within specified range. Here, we have taken Fuel, Blend ratio, Compression ratio, Injection pressure, and Load as variable parameters. The measuring parameters are Brake power, Brake specific fuel consumption, Brake thermal efficiency, Indicated thermal efficiency, Mechanical efficiency, Volumetric efficiency. The combination of factors and levels are as shown in table 1.

Table 1: Factors \& levels

\begin{tabular}{|l|c|c|c|}
\hline \multicolumn{1}{|c|}{ Factors } & Level 1 & Level 2 & Level 3 \\
\hline Blend Ratio & $\begin{array}{c}\text { D100B0 } \\
\text { (Pure Diesel) }\end{array}$ & $\begin{array}{c}\text { D50B50 } \\
(50 \% \text { Blend) }\end{array}$ & $\begin{array}{c}\text { D0B100 } \\
\text { (Pure Palm Seed Biodiesel) }\end{array}$ \\
\hline CompressionRatio (CR) & 14 & 16 & 18 \\
\hline Injection Pressure (Bar) & 160 & 175 & 9 \\
\hline Load (Kg) & 1 & 5 & 9 \\
\hline
\end{tabular}

\section{Experimental set up}

The set up consists of single cylinder, four stroke, and multi-fuel research engine in which loading has been provided by eddy current type dynamometer. If change from Petrol to Diesel or Diesel to Petrol is needed, it can be done by doing some necessary changes. In both modes, compression ratio has been varied without changing geometry of combustion chamber and without stopping the engine. For this, special tilting cylinder 
block arrangement has been designed. There is facility for changing injection point and spark point. Necessary instruments for combustion pressure, Diesel line pressure and crank-angle measurements have been provided in set up. These signals are interfaced with computer for pressure crank-angle diagrams. For interface airflow, fuel flow, temperatures and load measurements, required instruments have been given. The set-up has stand-alone panel box consisting of air box, two fuel tanks for duel fuel test, manometer, fuel measuring unit, transmitters for air and fuel flow measurements, process indicator and hardware interface. For cooling water, and calorimeter water flow measurement, Rotameter has been used. A battery, starter and battery charger have been provided for engine electric start arrangement. The setup enables study of VCR engine performance for brake power, indicated power, frictional power, BMEP, IMEP, brake thermal efficiency, indicated thermal efficiency, Mechanical efficiency, volumetric efficiency, specific fuel consumption, A/F ratio, heat balance and combustion analysis. Lab view based Engine Performance Analysis software package "Enginesoft" has been provided for on line performance evaluation. The testing rig is as shown in figure 2 . Table 2 shows the list of sensors and the list of engine specifications are as shown in table 3 [8].

Table 2: List of sensors

\begin{tabular}{|c|c|}
\hline F1 to F6 & Flow sensor for Fuel and Air \\
\hline W & Load sensor \\
\hline N & Engine Speed Sensor \\
\hline PT & $\begin{array}{l}\text { Cylinder Pressure Sensor, } \\
\text { Injection Pressure Sensor }\end{array}$ \\
\hline T1 to T6 & Temperature Sensors \\
\hline
\end{tabular}

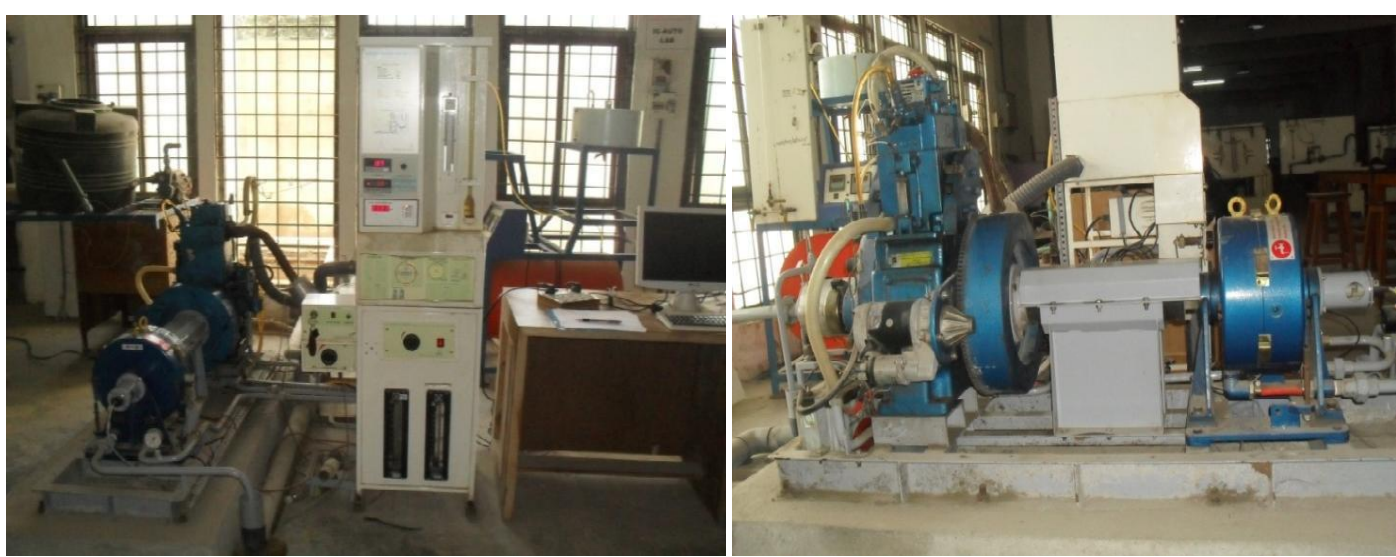

Fig 2: Engine testing rig

Table 3: Engine setup specifications[7]

\begin{tabular}{|l|l|}
\hline Engine manufacturer & Apex Innovations (Research Engine test set up) \\
\hline Software & Engine soft Engine performance analysis software \\
\hline Engine type & Single cylinder four stroke multi fuel research engine \\
\hline No. of cylinder & 1 \\
\hline Type of cooling & Water cooled \\
\hline Rated Power & $3.5 \mathrm{~kW} @ 1500 \mathrm{rpm}$ \\
\hline Cylinder diameter & $87.5 \mathrm{~mm}$ \\
\hline Orifice diameter & $20 \mathrm{~mm}$ \\
\hline Stroke length & $110 \mathrm{~mm}$ \\
\hline Connecting rod length & $234 \mathrm{~mm}$ \\
\hline Dynamometer & Type: eddy current, water cooled, with loading unit \\
\hline
\end{tabular}

VI Results and discussion

The results of BSFC are analyzed using Minitab 17. Minitab offers four types of designed experiments: factorial, response surface, mixture, and Taguchi (robust). The steps followed in Minitab to create, analyses, and graph an experimental design are similar for all design types. After conducting the analysis and entering the results, Minitab provides several analytical and graphing tools to understand the results. The $\mathrm{S} / \mathrm{N}$ ratio for optimal BSFC are coming under "Smaller-is-better" characteristic, which can be calculated as logarithmic transformation of the loss function.Experiment has been done for the four parameter which have been selected and sets of parameters by Minitab software and results have been found for those sets of parameters. Results for those sets are as shown in table 4. 
Parametric Optimization of Variable Compression Ratio Diesel Engine Fueled with Palm Seed ..

Table 4: Result table for SFC

\begin{tabular}{|c|c|c|c|c|}
\hline Ex. No. & $\begin{array}{c}\text { Speed } \\
(\text { RPM })\end{array}$ & $\begin{array}{c}\text { Torque } \\
(\mathrm{Nm})\end{array}$ & $\begin{array}{c}\text { BP } \\
(\mathrm{kW})\end{array}$ & $\begin{array}{c}\text { SFC } \\
(\mathrm{kg} / \mathrm{kWh})\end{array}$ \\
\hline 1 & 1530 & 1.87 & 0.3 & 1.5 \\
\hline 2 & 1511 & 9.33 & 1.48 & 0.44 \\
\hline 3 & 1467 & 16.1 & 2.47 & 0.36 \\
\hline 4 & 1425 & 16.21 & 0.25 & 0.35 \\
\hline 5 & 1501 & 1.61 & 1.44 & 1.83 \\
\hline 6 & 1516 & 9.07 & 1.38 & 0.5 \\
\hline 7 & 1506 & 8.75 & 2.49 & 0.48 \\
\hline 8 & 1478 & 16.09 & 0.28 & 1.38 \\
\hline 9 & 1533 & 1.75 & 1.87 \\
\hline
\end{tabular}

Main Effects Plot for Mean data and S/N ratio data are shown in Figure $3 \& 4$.

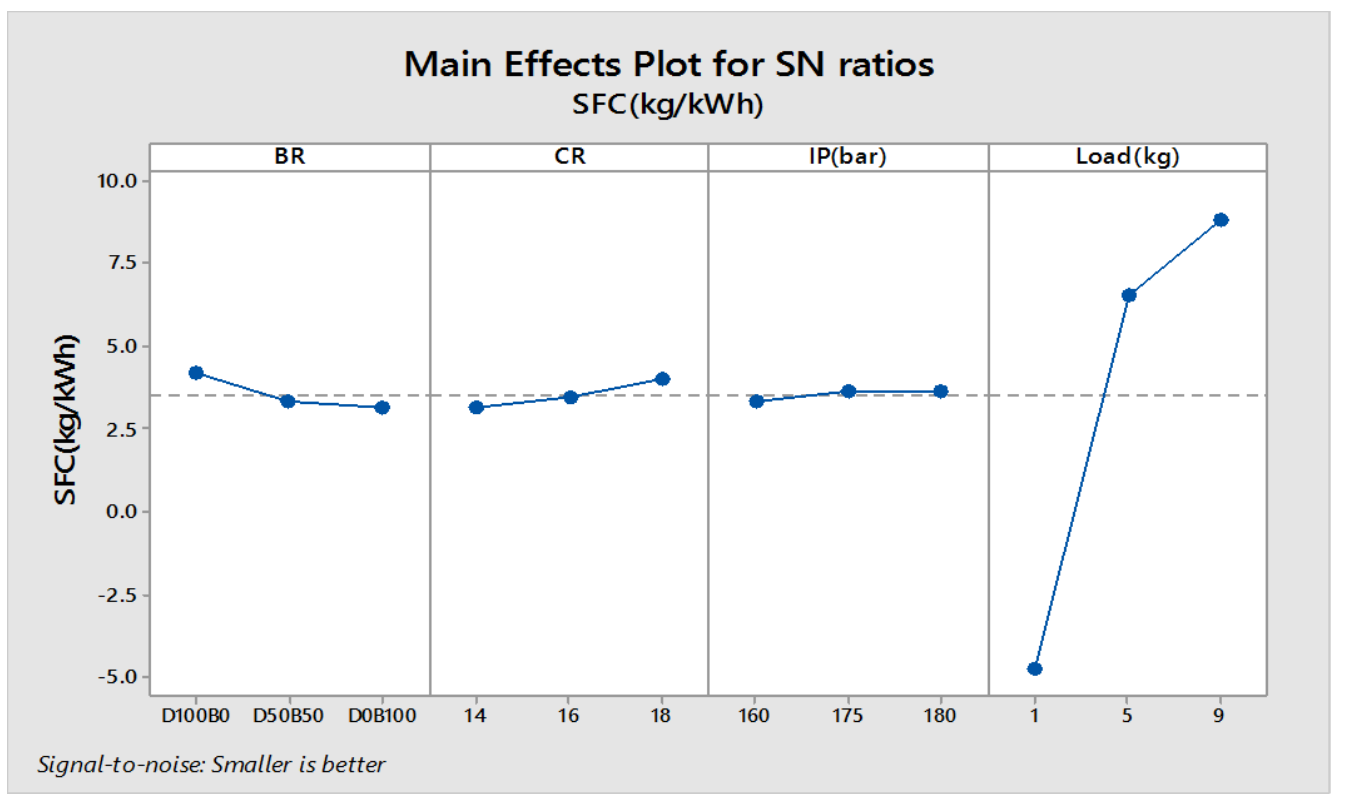

Fig 3: Main Effects Plot for SN ration for SFC

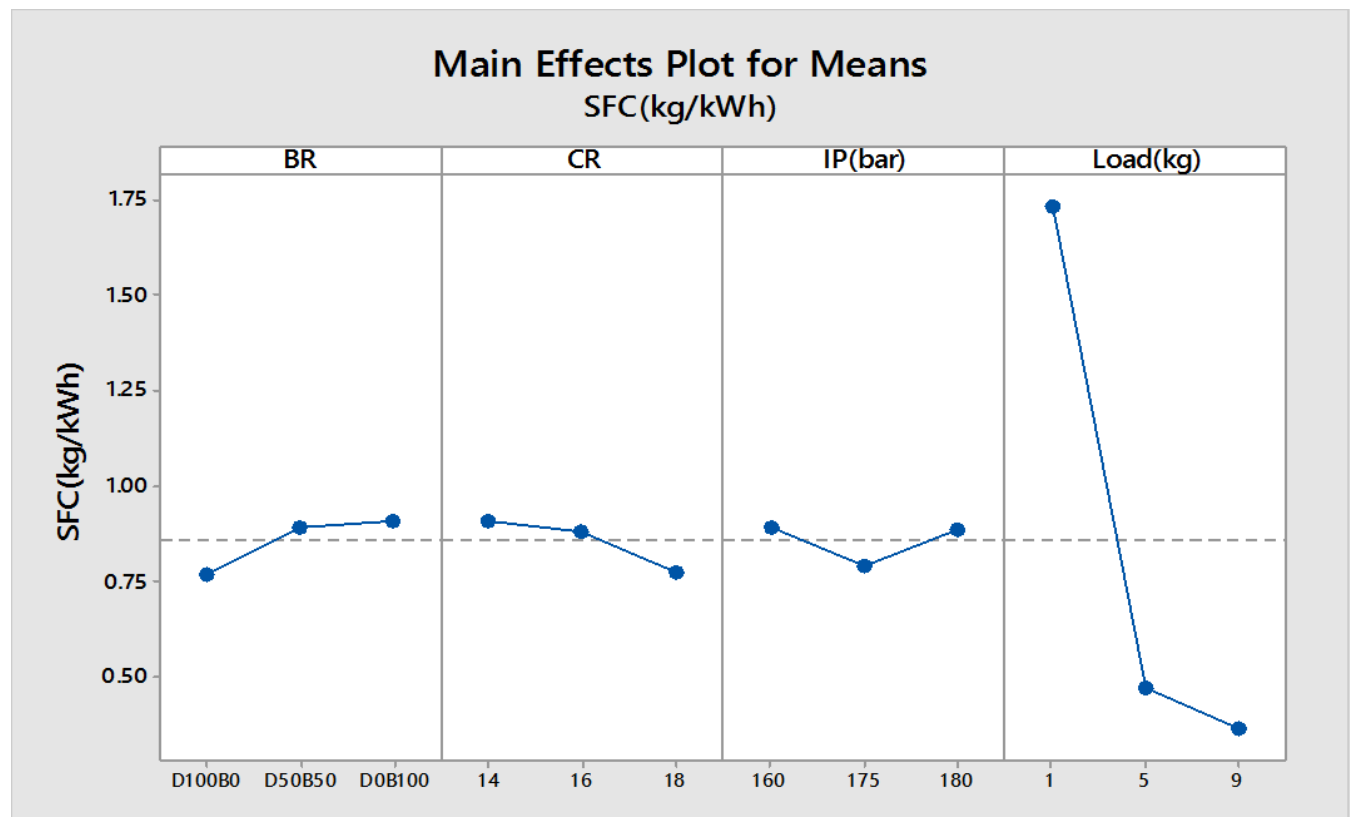

Fig 4: Main Effects Plot for Means for SFC 
Table 5 shows $\mathrm{S} / \mathrm{N}$ Ratio for BSFC.

Table 5: Response table for Signal to Noise $\operatorname{ratio}(\mathrm{S} / \mathrm{N})$ for $\mathrm{SFC}$

\begin{tabular}{|c|c|c|c|c|}
\hline Level & BR & CR & IP(bar) & Load(kg) \\
\hline 1 & 4.161 & 3.153 & 3.333 & -4.736 \\
\hline 2 & 3.297 & 3.429 & 3.634 & 6.509 \\
\hline 3 & 3.114 & 3.991 & 3.604 & 8.799 \\
\hline Delta & 1.047 & 0.838 & 0.301 & 13.535 \\
\hline Rank & 2 & 3 & 4 & 1 \\
\hline
\end{tabular}

Referring figure 3, in which we have considered smaller is better, we get smallest values of SN ratio for blend ratio for pure palm seed biodiesel (D0B100) which is 3.11422. We get smallest value of SN ratio for compression ratio of 14 which is 3.15257. We get smallest value of SN ratio for injection pressure of $160 \mathrm{bar}$ which is 3.33337. And we get minimum SN for load of $1 \mathrm{~kg}$ which is -4.73589 . We get highest $\mathrm{SN}$ ratios values for blend ratio for pure diesel (D100B0) which is 4.16102. Same for compression ratio of 18 which is 3.99066 . Same for injection pressure, we get it for IP of 175 bar which is 3.63437.Graph for main effects plot for means is as shown in figure 4. Highest value of mean for blend ratio is for palm seed biodiesel (D0B100) which is 0.91 . Highest value of mean is for compression ratio of 14 which is 0.91 . Highest value of mean for injection pressure is for IP of 160 bar which is 0.89 and we get highest value of mean in load for load of $1 \mathrm{~kg}$ which is 1.73. And, the lowest value of mean for blend ratio is for diesel (D100B0) which is 0.7666 . Lowest value of mean for compression ratio of 14 which is 0.7766 . Lowest value of mean for injection pressure is for IP of 175 bar which is 0.7933 and we get lowest value of mean in load for load of $9 \mathrm{~kg}$ which is 0.3633 .

In table 5 , level 1 is for the readings of three experiments performed on pure diesel (D100B). BR for level 1 shows average value of blend ratio for these three readings for diesel which is 4.161. CR shows average value of compression ratio for these three readings for diesel which is 3.153. As same, average IP is 3.333 and average load is -4.736 . Now values for level 2 and level 3 indicate same things. Delta is the difference between highest and lowestreading from all levels for particular parameter. And, according to these delta values, the ranks are given from highest delta to lowest delta as shown in table.

The S/N Ratio for different performance response are calculated at each factor level and the average effect are determined by taking the total of each factor level and divided by the number of data points in the total. The greater the difference between $\mathrm{S} / \mathrm{N}$ ratios values, the more is parametric influence. The parameter level having the highest $\mathrm{S} / \mathrm{N}$ ratio corresponds to the sets of parameters which indicates highest performance. Because of, we have considered it for Specific Fuel Consumption which must be as low as possible, we need to consider smaller is better factor.

So, from above discussion, we obtain table 6 for optimized set.

Table 6: Optimized set of parameter for Specific Fuel Consumption (SFC)

\begin{tabular}{|c|c|c|c|c|c|}
\hline BR & CR & IP(bar) & Load(kg) & SFC(kg/kWh) & SN ratio \\
\hline D100B0 & 18 & 175 & 9 & 0.13 & 10.0130 \\
\hline
\end{tabular}

From above table, we have been getting optimized set for pure diesel with compression ratio of 18 , injection pressure of $175 \mathrm{bar}$, load of $9 \mathrm{~kg}$ and specific fuel consumption of $0.13 \mathrm{~kg} / \mathrm{kWh}$ and we get SN ratio of 10.0130. As experiment has been done on Parametric Optimization of CI Engine using Palm Seed Biodiesel, it is necessary to find the performance parameters by using palm seed biodiesel for above optimized set. In table 7 , optimized set for palm seed biodiesel is shown.

Table 7: Optimized set of parameter for Specific Fuel Consumption (SFC) using Palm Seed Biodiesel

\begin{tabular}{|c|c|c|c|c|c|}
\hline BR & CR & IP(bar) & Load(kg) & SFC(kg/kWh) & SN ratio \\
\hline D0B100 & 18 & 175 & 9 & 0.2733 & 8.96624 \\
\hline
\end{tabular}

From above table, we have been getting specific fuel consumption of $0.2733 \mathrm{~kg} / \mathrm{kWh}$ and SN ratio of 8.96624 for optimized set for palm seed biodiesel with compression ratio of 18 , injection pressure of 175 bar, load of $9 \mathrm{~kg}$. Table 8 shows validation results specific fuel consumption.

Table 8: Validation Results for Specific fuel Consumption.

\begin{tabular}{|cc|}
\hline \multicolumn{3}{|c|}{ Validation Results for Specific fuel Consumption } \\
\hline \multicolumn{3}{|c|}{ For pure Diesel } \\
\hline Predicted Value & Experimental Value \\
\hline 0.13 & \\
\hline \multicolumn{3}{|c|}{ For Palm Seed Biodiesel } \\
\hline Predicted Value & 0.35 \\
\hline 0.27 & Experimental Value \\
\hline
\end{tabular}




\section{Conclusion}

The Taguchi method is found to be an efficient technique for quantifying the effect of control parameters. We can come to conclusion that, for minimum specific fuel consumption, we can select optimized set which is using pure Diesel with compression ratio of 18, injection pressure of $175 \mathrm{bar}$, load of $9 \mathrm{~kg}$ which gives specific fuel consumption of $0.35 \mathrm{~kg} / \mathrm{kWh}$ and SN ratio, 10.0130. And, for same set, using palm seed biodiesel, we get SFC of $0.2733 \mathrm{~kg} / \mathrm{kWh}$ and $\mathrm{SN}$ ratio 8.96624 .

\section{Journal Papers:}

\section{References}

[1] A. M. Liaquat,H. H., Masjuki,M. A. Kalam, \& Rizwanul Fattah, I. M. (2014). Impact of biodiesel blend on injector deposit formation. Energy, 72, 813-823. https://doi.org/10.1016/j.energy.2014.06.006

[2] M., Mofijur, H. H., Masjuki, M. A., Kalam, M. G., Rasul, A. E., Atabani, M. A., Hazrat, \& Mahmudul, H. M. (2015). Effect of Biodiesel-diesel Blending on Physico-chemical Properties of Biodiesel Produced from Moringa Oleifera. Procedia Engineering, 105(Icte 2014), 665-669. https://doi.org/http://dx.doi.org/10.1016/j.proeng.2015.05.046

[3] C. M., Patel, Pragna, P., Prof, R. P., Patel, T. M., \& Gaurav, P. (2015). Parametric Optimization of NO x Emissions using Taguchi Method for C . I Engine Fuel with Plastic Pyrolysis Oil. IJSRD - International Journal for Scientific Research \& Development, 3(1), 1373-1376.

[4] T. M., Patel, \&N. M. Bhatt, (2015). FEM based Taguchi method to Reduce the Automobile Structural Member Weight. GITJournal of Engineering and Technology, 8, 2-11.

[5] Balki, M. K., Sayin, C., \& Sarikaya, M. (2016). Optimization of the operating parameters based on Taguchi method in an SI engine used pure gasoline, ethanol and methanol. Fuel, 180, 630-637. https://doi.org/10.1016/j.fuel.2016.04.098

[6] K. B. Patel, P. T. M., Patel, \& S. C.Patel, (2013). Parametric Optimization of Single Cylinder Diesel Engine for Pyrolysis Oil and Diesel Blend for Specific Fuel Consumption Using Taguchi Method, 6(1), 83-88.

\section{Books:}

[7] Apex Innovations Pvt. Ltd. Sangali, Maharashtra state, India. RESEARCH ENGINE TEST SET UP, 1-75. 